\title{
Patient-centered Communication
}

\author{
Do Patients Really Prefer It?
}

Sara L. Swenson, MD, Stephanie Buell, BA, Patti Zettler, BA, Martha White, BS, Delaney C. Ruston, MD, Bernard LO, MD

OBJECTIVE: To investigate patient preferences for a patientcentered or a biomedical communication style.

DESIGN: Randomized study.

SETTING: Urgent care and ambulatory medicine clinics in an academic medical center.

PARTICIPANTS: We recruited 250 English-speaking adult patients, excluding patients whose medical illnesses prevented evaluation of the study intervention.

INTERVENTION: Participants watched one of three videotaped scenarios of simulated patient-physician discussions of complementary and alternative medicine (CAM). Each participant watched two versions of the scenario (biomedical vs. patientcentered communication style) and completed written and oral questionnaires to assess outcome measurements.

MEASUREMENTS AND MAIN RESULTS: Main outcome measures were 1) preferences for a patient-centered versus a biomedical communication style; and 2) predictors of communication style preference. Participants who preferred the patient-centered style (69\%; 95\% confidence interval [CI], 63 to 75$)$ tended to be younger $(82 \%[51 / 62]$ for age $<30 ; 68 \%$ [100/148] for ages 30-59; 55\% [21/38] for age $>59 ; P<.03)$, more educated (76\% [54/71] for postcollege education; $73 \%$ [94/128] for some college; $49 \%$ [23/47] for high school only; $P=.003)$, use CAM $(75 \%[140 / 188]$ vs. $55 \%[33 / 60]$ for nonusers; $P=.006)$, and have a patient-centered physician $(88 \%$ [74/84] vs. $30 \%$ [16/54] for those with a biomedical physician; $P<.0001)$. On multivariate analysis, factors independently associated with preferring the patient-centered style included younger age, use of herbal CAM, having a patient-centered physician, and rating a "doctor's interest in you as a person" as "very important."

Received from the Program in Medical Ethics (SLS, SB, PZ, MW, DCR, BL) and Division of General Internal Medicine (SLS, BL), University of California, San Francisco, Calif; and Department of Medicine (DCR), University of Washington, Seattle, Wash.

Presented in part at the 25th annual meeting of the Society of General Internal Medicine in Atlanta, Ga, May 2, 2002.

Address correspondence and requests for reprints to Dr. Swenson: University of California, San Francisco, Box 0320, 400 Parnassus Avenue, San Francisco, CA 94143-0320 (e-mail: swenson@medicine.ucsf.edu).
CONCLUSIONS: Given that a significant proportion of patients prefer a biomedical communication style, practicing physicians and medical educators should strive for flexible approaches to physician-patient communication.

KEY WORDS: patient-centered care; physician-patient relations; knowledge, attitudes, practice; comparative study; patient satisfaction.

J GEN INTERN MED 2004;19:1069-1079.

$\mathbf{M}$ edical educators ${ }^{1}$ and researchers ${ }^{2}$ advocate a patient-centered approach to the medical interview in which physicians ascertain and incorporate patients' expectations, feelings, and illness beliefs. ${ }^{3}$ Some studies have found associations between patient-centered communication and patient satisfaction, ${ }^{4-7}$ treatment adherence, ${ }^{7,8}$ medical outcomes, ${ }^{2,7,9-11}$ and decreased rates of malpractice claims. ${ }^{12}$ Furthermore, clinician failure to elicit and discuss patient expectations in the medical visit predicts dissatisfaction with the visit and persistence of symptoms. ${ }^{13-15}$ However, evidence for the impact of patient-centered communication on medical outcomes is mixed ${ }^{16-19}$; in wellconducted trials, interventions to enhance patient-centered communication among physicians failed to improve patient medical outcomes ${ }^{20}$ and satisfaction. ${ }^{21}$ Moreover, little empirical evidence exists about what physician communication styles patients in the United States prefer and whether these preferences vary according to patient characteristics. ${ }^{22}$ Such information could enhance our understanding of how communication style affects outcomes, help physicians tailor their communication to individual patient preferences and, ultimately, improve patient satisfaction and health outcomes.

We conducted a randomized study of patient preferences for a patient-centered versus a biomedical physician communication style in which the physician is directive and focuses primarily on biomedical issues. We used videotapes of simulated office visits in which a patient broaches the use of complementary and alternative medicine (CAM) with her physician. Our primary study objective was to compare patient preferences for a patient-centered versus a biomedical communication style as depicted on the videotapes. Secondary objectives were to identify 
predictors of preferring a given communication style and to determine whether physician communication style predicts patient disclosure of CAM use.

\section{METHODS}

\section{Study Participants and Recruitment}

We recruited 250 patients attending urgent care (231) or general internal medicine clinics (19) at an academic medical center during September 2001 to May 2002. Eligible patients were English-speaking adults age 18 or older. Based on assessment by the clinic triage nurse, who was not involved in the study, we excluded patients whose medical conditions would preclude watching or evaluating the videotapes (due to significant acute illness, dementia, and unstable psychotic disorders).

To recruit a representative sample on each study day, the study administrator (SB) approached the first eligible patient for recruitment. If that patient declined to participate or if the study administrator found the patient ineligible due to limited English proficiency or dementia, she approached the next eligible patient. After preliminary data analysis revealed a paucity of geriatric patients, we altered recruitment to enrich our sample for elderly participants. To recruit the latter 100 participants, the study administrator initially screened only patients age 65 and older for eligibility. If no patients over 65 were waiting, she recruited the next eligible patient of any age. To minimize selection bias, the study administrator recruited participants during different days of the week and times of day. All participants gave informed consent. Participants who completed the study were reimbursed with a $\$ 20$ grocery gift card. The institutional review board at the University of California, San Francisco approved the study.

\section{Study Instruments and Measurements}

Videotapes. The study videotapes depicted common scenarios in which patients broach their use of CAM. We chose CAM use because it occurs frequently ${ }^{23-26}$ and is a sensitive topic that often goes unaddressed in the clinical encounter. ${ }^{24,27}$ Although several authors have documented benefits of discussing CAM use with patients ${ }^{28-35}$ and recommended that physicians do so, ${ }^{36-40}$ it is not known how patients prefer physicians to discuss CAM.

To evaluate patient preferences across a spectrum of risk-benefit situations, we developed three videotape scenarios: (I) "Unnecessary Cost," (II) "Uncertain Efficacy," and (III) "Potential Harm" (see Box). We chose these scenarios based on focus group discussions with physician experts regarding situations involving patient CAM use that occurred commonly in their clinical practice. The Unnecessary Cost scenario depicted a patient taking an expensive, "individually formulated" vitamin preparation that offered no clear benefit over a regular multivitamin. In Uncertain Efficacy, the patient was attempting to lower

\begin{tabular}{|c|c|c|c|}
\hline \multicolumn{4}{|c|}{ Videotape Scenarios } \\
\hline Actors & $\begin{array}{c}\text { Unnecessary } \\
\text { Cost }\end{array}$ & $\begin{array}{c}\text { Uncertain } \\
\text { Efficacy }\end{array}$ & $\begin{array}{c}\text { III } \\
\text { Potential } \\
\text { Harm }\end{array}$ \\
\hline Patient & $\begin{array}{c}\text { Older white } \\
\text { woman }\end{array}$ & $\begin{array}{c}\text { Middle-aged } \\
\text { white man }\end{array}$ & $\begin{array}{c}\text { Middle-aged } \\
\text { white woman }\end{array}$ \\
\hline Doctor & $\begin{array}{c}\text { Older white } \\
\text { man }\end{array}$ & $\begin{array}{c}\text { Middle-aged } \\
\text { black man }\end{array}$ & $\begin{array}{c}\text { Middle-aged } \\
\text { white woman }\end{array}$ \\
\hline
\end{tabular}

his blood pressure by using an herbal supplement with uncertain risks and benefits. In both of these scenarios, the patient brings in the dietary supplement and asks the doctor for her opinion regarding its use. The Potential Harm scenario showed a patient taking an ephedra-containing weight loss supplement that increased her previously controlled hypertension to dangerous levels. In this scenario, the doctor detects the patient's use of the supplement by asking if she is doing anything new that might explain her elevated blood pressure. We also varied scenarios with respect to patient and physician gender-ethnicity concordance (Box).

For each scenario, we developed 2 distinct versions for a total of 6 tapes. One version depicted a more biomedically focused communication style (A); the second, a "patientcentered" style (B). ${ }^{41,42}$ To create the scripts for the biomedical versions, we interviewed a convenience sample of 15 experienced primary care physicians, 5 of whom had a special interest in CAM, regarding their typical responses to patient questions about CAM. For the patient-centered versions, a working group of experts in doctor-patient communication helped to develop the scripts. Each "patientcentered" version included those elements that have been evaluated empirically or mentioned in the literature on patient-centered communication: 1) developing an understanding of the patient as a person; 2) conveying empathy; and 3) finding common ground regarding treatment and goals of care. ${ }^{3,16,17,41,43}$

Within each CAM use scenario, the videotapes differed only with respect to the doctor's communication style. Each version was identical in terms of patient history and clinical presentation. In both versions, the doctor offered the same "bottom-line" recommendation about the CAM supplement and presented similar information regarding its risks or uncertainties. Each utilized the same professional actors who employed similar body language, tone of voice, and conversational pace. Mean videotape lengths were 2:43 minutes. For each pair, the "patient-centered" version was longer (mean 16 seconds; range 2 to 28 seconds), and the patient spoke for a greater percentage of the time $(47 \% \mathrm{vs}$. $38 \%$ on average). We showed all three versions of the videos to 10 attending and resident physicians in general internal medicine, to assess the videos' face validity. (Samples of the study videotapes can be viewed at http://dgim.ucsf.edu/ swenson/compaltvideos.html). 
Predictor Variables. We developed a 20-item questionnaire to assess participants' demographic and clinical characteristics, CAM use, and satisfaction with their current physician. Using validated questions from prior studies of patient satisfaction (see Appendix A available online at www.jgim.org), ${ }^{8,44}$ we also developed a 7 -item scale to assess participant opinions regarding their interactions with physicians. This "Important Aspects of Doctoring" scale had a Cronbach's $\alpha$ of 0.70 .

Outcome Measurements. Our primary outcome was participants' preference for the patient-centered or biomedical communication style as assessed by the following question: "Thinking back to the videotapes you just watched, which of the doctors did you prefer?" We assessed participants' perceptions about their own physician's communication style by asking: "Which of the two doctors in the videotapes had a style that was most like your own regular doctor's style?" To gain a more nuanced understanding of participants' preferences, we developed an 11-item Physician Assessment Questionnaire (see Appendix B available online at http://www.jgim.org). Likert scale items were adapted from validated patient satisfaction scales to assess three dimensions of care: global satisfaction, patient centeredness, and other characteristics. ${ }^{8,44}$ The patient-centeredness dimension included items on developing an understanding of the patient as a person, conveying empathy, and finding common ground ${ }^{41,43}$ that we hypothesized would differ for the biomedical and patient-centered versions of the videotape. Six additional items measured global satisfaction ${ }^{8}$ and other physician characteristics that had no a priori reason to differ between tape versions. For the qualitative interviews, we asked: 1) "Thinking back to the videotapes you just watched, which doctor did you prefer and why?" and 2) "What was the biggest difference between the two doctors in the videotapes?"

Instrument Development. Two investigators (SLS, SB) pilot tested early versions of the study instruments and interview questions among 20 health care professionals, healthy volunteers, and elderly patients for clarity, flow, and ease of completion. Based on pilot data, we eliminated and revised several questions and reworded most negatively phrased questions to achieve satisfactory patient comprehension.

\section{Randomization and Study Procedures}

Prior to the study day, one investigator (SLS) randomized consecutive participants to view a specific videotape scenario (I, II, or III) with either the biomedical (A) or the patient-centered (B) version first. Randomization was carried out in blocks of 12 participants. The study administrator remained blinded to scenario and tape order until after each subject had undergone recruitment and agreed to participate, at which time participants viewed the preassigned videotape scenario and tape order. After watching the first videotape, participants completed the Physician Assessment Questionnaire. Next, they watched the second tape and completed an identical questionnaire for the second doctor. They then answered questions regarding which doctor they preferred and which doctor's style best resembled that of their own primary doctor. They also completed the demographic questionnaire, including the Important Aspects of Doctoring scale. Finally, participants underwent qualitative interviews, which were audiotaped and transcribed verbatim for analysis. The study administrator used standardized prompts to encourage participants to elaborate or clarify answers.

\section{Data Analysis}

Sample Size Calculations. Our primary outcome was preferences for a patient-centered versus a biomedical communication style in the videotaped doctor-patient discussions (two-tailed comparison). We thought that an effect size of $20 \%$ would be clinically meaningful (e.g., $40 \%$ of patients preferring the biomedical and 60\% preferring the patient-centered doctor). To detect predictors of communication style preference, we set $\alpha$ at 0.05 (two-sided) and power at 0.80 and estimated a $10 \%$ dropout rate to yield a total sample size of $230 .^{45}$

General. We utilized SPSS (versions 6 and 11; SPSS Inc., Chicago, Ill) for all quantitative data analysis. Data were double entered, cross-checked, and cleaned. Due to clustering of responses, we collapsed Likert scale data from the Important Aspects of Doctoring scale into dichotomous variables (irrelevant, not important, somewhat important vs. important, extremely important). We rescaled responses so that higher scores represented higher levels of importance or agreement. We performed bivariate analysis to test our primary outcome variable with the following independent variables: participant gender, age, ethnicity, education, income, presence of chronic illness or disability, prescription medication use, number of daily medications, and selfperceived health status and control over health. We also investigated age (Scenario I) and ethnicity and gender concordance (Scenarios I, II, III, and all scenarios). We used Pearson $\chi^{2}$ analysis or Fisher's exact tests (two-tailed), where appropriate, and Wilcoxon signed-rank tests for nonnormally distributed variables. For testing hypotheses related to proportion differences, we performed a two-sided difference of proportions test using a normal probability distribution, adjusting for overlapping populations. Unless otherwise stipulated, statistical significance was set a priori at $P<.05$.

Multivariate Analysis. For the multivariate model, we selected substantive variables originally posited to answer the primary hypothesis and secondary variables significant at the 0.05 level on bivariate analyses. We used a stepwise block procedure to enter variables into the logistic regression model, entering first variables that are beyond physicians' 
control and last, tape order. Variables included gender, ethnicity, education, age, and presence of disability or chronic illness (block 1); participant use of herbal medicine, communication style of the participants' own physician, and two items on the Important Aspects of Doctoring scale (physician open-mindedness and interest in the patient as a person) (block 2); and tape order and gender concordance (block 3). For participant use of CAM, we chose use of herbal medicine because it yielded a better fitting model than did overall CAM use. We used the Hosmer-Lemeshow goodness-of-fit deciles of risk test for determining the appropriateness of the logistic regression model because many predictor variables were categorical and our sample size was less than $400 .^{46}$

Qualitative Analysis. A detailed description of the qualitative findings will be published separately; we briefly summarize our methods here. We used the method of constant comparisons to develop a preliminary coding scheme. Two of the study investigators (SLS, PZ) independently coded all responses. The research team (SLS, PZ, BL) then analyzed and discussed coding discrepancies and revised and refined the coding scheme. The final scheme consisted of 34 coding items and 12 themes.

\section{RESULTS}

\section{Participant Characteristics}

We approached a total of 418 patients for study participation. Forty-eight were excluded due to cognitive impairment or an inability to speak English, and 120 declined to participate, for a response rate of 68\% (250/ 370). Our sample was gender balanced, ethnically diverse, and relatively young, healthy, and well educated (Table 1). Our sample resembled the overall patient population in the urgent care clinic with respect to gender and age (data available from authors on request). As expected from an urgent care population, slightly over half had a regular physician. Among participants with regular physicians, $71 \%$ reported being "extremely" or "very" satisfied with them. Sixty-one percent rated their own physician as having a style similar to that of the patient-centered doctor in the videotape. Three fourths of participants (189/249) reported using CAM within the past year. The most commonly used forms included dietary supplements (41\%; 103/249), massage $(38 \% ; 95 / 249)$, relaxation or meditation $(38 \%$; 93/248), and herbal therapies (36\%; 89/250).

\section{Preferred Physician Communication Style}

Most participants preferred the videotape doctor who exhibited a patient-centered communication style $169 \%$; 95\% confidence interval [CI], 63 to 75). This preference was similar across the three videotape scenarios (I: $67 \%$ vs. $33 \%$, $\mathrm{Z}=0.02, P=.99$; II: $74 \%$ vs. $26 \%, Z=0.04, P=.97$; III: $67 \%$ vs. $33 \%, z=0.02, P=.98)$. We therefore grouped tapes
Table 1. Participant Characteristics

\begin{tabular}{|c|c|}
\hline Characteristic & No. (\%) \\
\hline \multicolumn{2}{|l|}{ Demographics } \\
\hline Female & $138(55)$ \\
\hline \multicolumn{2}{|l|}{ Ethnicity } \\
\hline White or European American & $133(59)$ \\
\hline Black or African American & $40(18)$ \\
\hline Asian or Asian American & 37 (16) \\
\hline Hispanic & $17(8)$ \\
\hline Median age, y (range) & 39 (18 to 85$)$ \\
\hline \multicolumn{2}{|l|}{ Education } \\
\hline High school graduate or less & 47 (19) \\
\hline Some college/college graduate & $128(52)$ \\
\hline Postcollege education & $72(29)$ \\
\hline \multicolumn{2}{|l|}{ Yearly income, $\$$} \\
\hline$<20,000$ & $57(24)$ \\
\hline 20,000 to 39,999 & $55(23)$ \\
\hline 40,000 to 59,999 & $43(18)$ \\
\hline $60,000+$ & $87(36)$ \\
\hline \multicolumn{2}{|l|}{ Health and health care characteristics } \\
\hline Chronic medical problem or disability & $69(28)$ \\
\hline Daily prescription medicine & $117(47)$ \\
\hline $\begin{array}{l}\text { Mean number of prescription medicines } \\
\text { (range) }\end{array}$ & 3.4 ( 1 to 25$)$ \\
\hline $\begin{array}{l}\text { Self-rated health status excellent or very } \\
\text { good }\end{array}$ & $118(48)$ \\
\hline Current regular MD & $139(56)$ \\
\hline \multicolumn{2}{|l|}{ Own MD style* } \\
\hline Biomedical & $54(39)$ \\
\hline Patient-centered & $84(61)$ \\
\hline $\begin{array}{l}\text { Satisfaction with own MD } \\
\text { (extremely or very)* }\end{array}$ & $99(71)$ \\
\hline \multicolumn{2}{|l|}{ CAM usage } \\
\hline Any CAM use & $189(76)$ \\
\hline $\begin{array}{l}\text { Use of supplements, herbs, or folk } \\
\text { remedies }\end{array}$ & $137(55)$ \\
\hline Disclosure of CAM use to $\mathrm{MD}^{\dagger}$ & $33(50)$ \\
\hline
\end{tabular}

* In subset of participants with a regular $M D(N=139)$.

${ }^{\dagger}$ In subset of participants with a regular MD who use supplements, herbs, or folk remedies $(N=70)$.

CAM, complementary and alternative medicine.

from all scenarios into either biomedical or patient-centered versions for subsequent analyses.

\section{Bivariate Predictors of Preferred Communication Style}

Demographic and Clinical Predictors. Although most participants favored the patient-centered style, certain subgroups were less likely to prefer it (Table 2). Older participants, participants with less formal education, and nonusers of CAM were significantly less likely than their counterparts to prefer the patient-centered doctor. Gender discordance was also associated with a tendency to prefer the biomedical doctor only for the female physician (Scenario III). No other demographic or clinical predictors were associated with communication preference, including ethnicity and age concordance. Two Important Aspects of Doctoring items were significant predictors of preferring 
Table 2. Bivariable Predictors of Preferred Physician Interviewing Style $(N=250)$

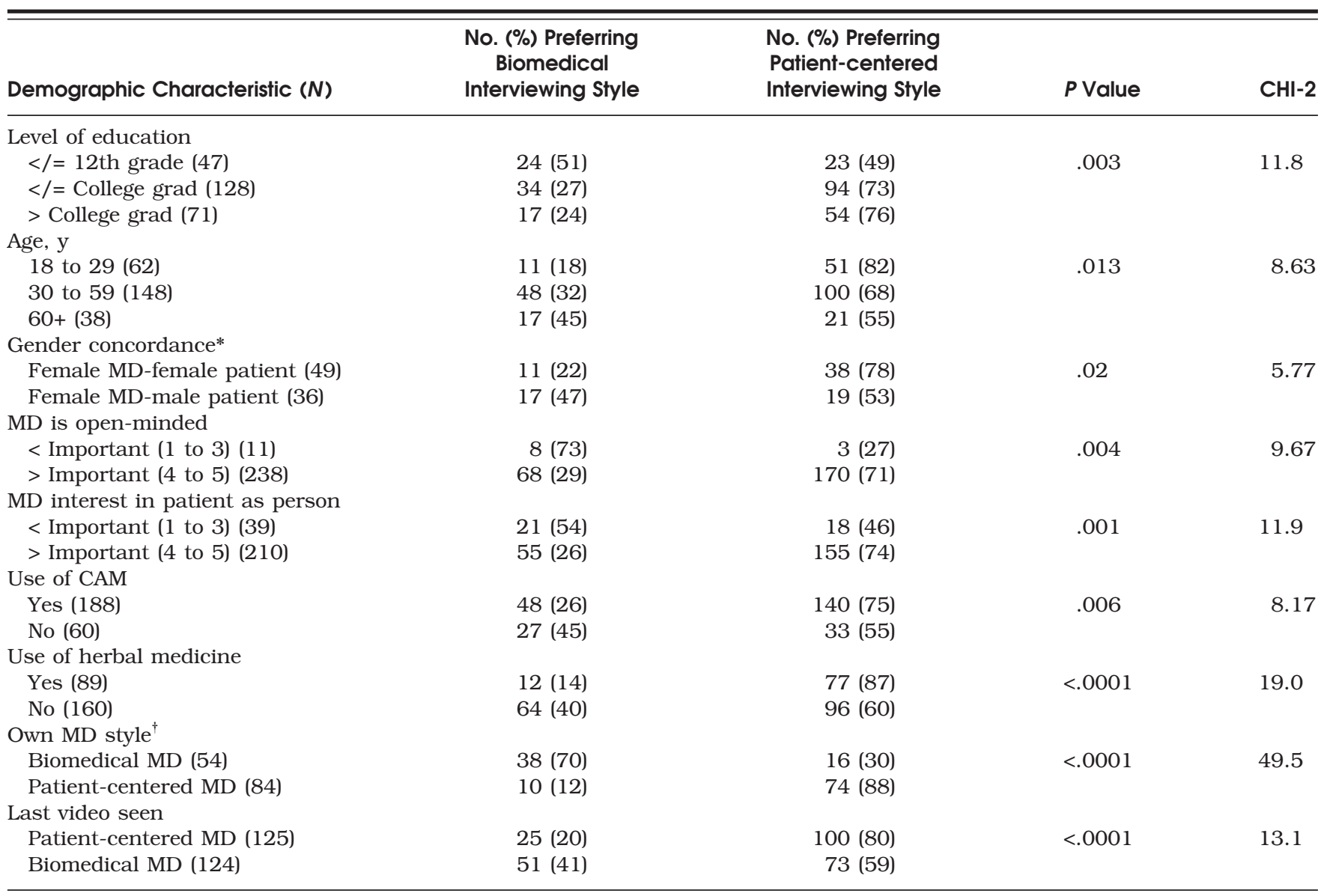

* Subset of participants $(N=85)$ who viewed Tape Pair I.

${ }^{\dagger}$ Subset of participants $(N=138)$ who had a current regular physician.

CAM, complementary and alternative medicine.

a patient-centered doctor: the doctor's interest in you as a person and the doctor is open-minded (Table 2).

Previous Health Care Experiences. Participants were more likely to prefer the videotaped doctor whose style was the same as their own physician's (Table 2). Among participants who were "completely" satisfied with their physician, this effect was more pronounced; 91\% (32/35) of participants who were satisfied with their own biomedical physician preferred the biomedical doctor in the videotape and $92 \%(59 / 64)$ of those who were satisfied with their own patient-centered physician preferred the patient-centered doctor.

Tape Order. Participants were more likely to prefer the second communication style they viewed. Among those who viewed the patient-centered tape second, 80\% (100/ 125) preferred the patient-centered doctor, whereas only $59 \%(73 / 124)$ of those who viewed the biomedical tape second preferred the patient-centered doctor $\left(\chi^{2}=13.1\right.$; $P=.001)$. This recency effect was seen with all three CAM scenarios.

\section{Multivariate Predictors of Preferred Communication Style}

Multivariate analysis revealed four significant predictors of participant preference for the patient-centered communication style when the effects of tape order were controlled (Table 3). These were having a patient-centered physician, rating "the doctor's interest in you as a person" as "more important," and using herbal medicine in the past year. In contrast, older participants were less likely to prefer a patient-centered approach. The goodness-of-fit (HL-GOF) test for the final multivariate model was 0.42 .

\section{Likert Scale Ratings of Physician Communication Skills}

Data from the Physician Assessment Questionnaire showed that participants rated the patient-centered doctors more positively, especially with respect to dimensions of patient-centered communication (e.g., "suggesting a good plan for helping the patient”; Table 4). Conversely, differences between patient-centered and biomedical versions 
Table 3. Multivariate Predictors of Preference for a Patient-centered Interviewing Style*

\begin{tabular}{|c|c|c|c|}
\hline Independent Variable & Odds Ratio & $\begin{array}{c}95 \% \\
\text { Confidence } \\
\text { Interval }\end{array}$ & $P$ Value \\
\hline 18 to 29 & Reference group & & \\
\hline 30 to 59 & 0.23 & (0.09 to 0.63$)$ & .004 \\
\hline $60+$ & 0.19 & (0.06 to 0.64$)$ & .008 \\
\hline Own MD style (patient-centered vs. biomedical) & 15.9 & (6.80 to 37.3$)$ & $<.0001$ \\
\hline Last video seen (patient-centered vs. biomedical) & 5.13 & (2.27 to 11.6$)$ & $<.0001$ \\
\hline
\end{tabular}

* Other covariates were gender, ethnicity, education, and presence of a disability or chronic illness (block 1); one item on the Important Physician Characteristics scale (physician open-mindedness) (block 2); and gender concordance (block 3).

were smaller for those dimensions that were not specific to patient-centered techniques and were not statistically significant for two of these (decisiveness and knowing the risks and benefits of CAM).

\section{Qualitative Data}

What Participants Liked About Physician Communication Style. Participants who preferred the patient-centered doctor cited being "interested in the patient as a person," devising a "good plan" for the patient, and "listening more to the patient." As one participant remarked, "the [patientcentered] doctor treated the patient more as a person, listening to what her goals were...and trying to work out a plan that would work much more humane." A second noted that the patient-centered doctor "heard the same information as the [biomedical] doctor, but seemed more openminded about why she was doing what she was doing, and...was more sort of taking into consideration her feelings."

In contrast, those who preferred the biomedical doctor found her "direct," "straightforward," or "decisive" style more appealing. One participant preferred the biomedical doctor "because she wanted action, like right now.... She gave it her best shot right away." Another remarked: "I think the doctor should take more of a leadership role, and I think the [biomedical] doctor did." Still another appreciated this doctor's willingness to take a stand; for example: "He wasn't all question, he was to the point. He answered the question like he knew what he was talking about. I didn't have any doubt."

Seeing Both Sides. Participants who watched the same videotape scenario discerned key features of the communication styles yet evaluated those styles differently. For example, a participant who preferred the biomedical doctor noted that he "was dealing more with the facts and the

Table 4. Mean Likert Scale Responses to Biomedical Versus Patient-centered Videotapes*

\begin{tabular}{|c|c|c|c|}
\hline Item No. & Dimensions of Care Items & $\begin{array}{l}\text { Biomedical } \\
\text { Mean }( \pm S D)\end{array}$ & $\begin{array}{c}\text { Patient-centered } \\
\text { Mean }( \pm S D)\end{array}$ \\
\hline & Patient-centered characteristics & & \\
\hline 1 & The doctor suggested a good plan for helping the patient. ${ }^{\dagger}$ & $3.5( \pm 1.7)$ & $2.1( \pm 1.2)$ \\
\hline 2 & The doctor seemed open-minded. ${ }^{\dagger}$ & $3.3( \pm 1.6)$ & $2.5( \pm 1.4)$ \\
\hline 3 & The doctor was interested in the patient as a person. ${ }^{\dagger}$ & $2.4( \pm 1.3)$ & $1.9( \pm 1.0)$ \\
\hline 4 & The doctor gave the patient a chance to say what was on his or her mind. ${ }^{\dagger}$ & $2.4( \pm 1.2)$ & $1.7( \pm 0.9)$ \\
\hline 5 & $\begin{array}{l}\text { The doctor gave the patient his/her full attention. }{ }^{\dagger} \\
\text { Other characteristics }\end{array}$ & $2.1( \pm 1.1)$ & $1.6( \pm 0.8)$ \\
\hline 6 & The doctor took the patient's problems seriously. ${ }^{\dagger}$ & $2.3( \pm 1.3)$ & $1.7( \pm 0.9)$ \\
\hline 7 & The doctor communicated in simple, clear language. & $2.2( \pm 1.0)$ & $1.9( \pm 0.9)$ \\
\hline 8 & The doctor seemed to know about the risks and benefits of alternative medicine. & $2.8( \pm 1.5)$ & $2.7( \pm 1.2)$ \\
\hline 9 & $\begin{array}{l}\text { The doctor seemed decisive. } \\
\text { Global measurements }\end{array}$ & $2.8( \pm 1.5)$ & $2.9( \pm 1.5)$ \\
\hline 10 & This is a doctor I would trust. ${ }^{\dagger}$ & $2.7( \pm 1.5)$ & $2.1( \pm 1.3)$ \\
\hline 11 & I would recommend this doctor to my friends. ${ }^{\dagger}$ & $2.2( \pm 1.1)$ & $1.7( \pm 0.9)$ \\
\hline
\end{tabular}

* In the Physician Assessment Questionnaire, respondents were asked to rate their level of agreement or disagreement with the following statements regarding the videotapes. Question 11 utilized a 5-point Likert scale ranging from (1) definitely yes to (5) definitely not. All remaining questions utilized a 7-point Likert scale ranging from (1) very strongly agree to (7) very strongly disagree. Due to multiple comparisons, the level of statistical significance was set at $\mathrm{P}<.001$.

${ }^{\dagger} \mathrm{P}<.0001$.

${ }^{\ddagger} \mathrm{P}>.01$. 
[patient-centered doctor] was dealing more with...trying to make the patient feel listened to, sympathized with. The facts are what are useful to me." After viewing the same tape pair, another participant had similar observations but preferred the patient-centered doctor's approach: "In terms of attitude, the [patient-centered] one was better. But in terms of getting information quickly, the [biomedical] doctor was better."

Relationship with Own Physician Style. Some participants sought out their preferred communication style in their physicians. For example, one noted, "I like to choose my doctors on how personable they are and if it's somebody I'm comfortable with. And if I'm not, I just look for another doctor.... [The patient-centered doctor] is more how my doctor is here. And that is what I look for." Others disliked a videotaped doctor's style that departed from their past experiences. For example, one individual who preferred the biomedical doctor noted that the patient-centered doctor "didn't use any words that were typical words that a doctor would use...I felt [he] was being a phony."

\section{CAM Disclosure}

Over half of participants $(55 \% ; 137 / 250)$ reported using CAM therapies with potential side effects or drug-drug interactions (e.g., supplements, herbal medicine, and folk remedies). Among participants with regular physicians who had used such potentially harmful CAM, 50\% (33/66) had told their own physician about their use of it. Participants who thought that their current physician had a biomedical approach were equally likely to have disclosed their CAM use $(50 \% ; 13 / 26)$ as those who thought their physician was patient centered $(50 \% ; 20 / 40)$.

\section{DISCUSSION}

Medical educators, ${ }^{1}$ researchers, ${ }^{2}$ and consensus panels ${ }^{3}$ recommend teaching and practicing patientcentered communication. However, our study represents the first randomized study of communication style preferences among U.S. patients. We found that $31 \%$ of subjects preferred a more traditional, directive communication style. Certain patients were more likely to prefer the patientcentered style, including those who characterized their own physician as patient centered, valued physician interest in the patient as a person, and were younger than 65 .

\section{Comparison to Existing Literature: Communication Preferences and Predictors}

Other studies have also found that most participants prefer a patient-centered style, ${ }^{47}$ that patients prefer the perceived decision-making style of their own physician, ${ }^{22}$ and that older patients prefer a more directive style. ${ }^{16,19,22,48,49}$ Similar to our findings, Schmittdiel et al. observed an association between gender concordance and patient prefer- ences for a female but not a male doctor. ${ }^{50}$ However, unlike other studies, we did not find that male gender, ${ }^{19}$ lower levels of education, ${ }^{16,19,48,49}$ lower socioeconomic class, ${ }^{19,22}$ or more severe levels of illness ${ }^{19,49}$ were associated with preferring the more "directive," biomedical style.

Although patient communication preferences in our study did not vary across different CAM scenarios, other studies have found preference variation across clinical scenarios. ${ }^{51}$ McKinstry found that UK patients were more likely to prefer a directive style when evaluating doctor-patient interactions about a physical problem but preferred either style equally for interactions involving depression or smoking cessation. ${ }^{22}$ A randomized trial of a "directive" or "sharing" physician style among British patients found higher satisfaction rates with a "directive" style when visits involved physical problems and equivalent rates when visits were longer or involved counseling, or chronic or psychological illnesses. ${ }^{52}$

\section{Implications}

Our finding that almost a third of patients prefer a nonpatient-centered approach may help to explain the mixed impact of patient-centered communication on satisfaction and medical outcomes. Patient communication preferences may act as a key intermediary between physician communication style and patient outcomes. Several studies suggest that patient perceptions of patient centeredness or patient-physician congruence of interviewing styles are better predictors of trust, visit satisfaction, ${ }^{19}$ and medical outcomes ${ }^{17}$ than is actual physician patient centeredness.

Given this diversity of patient communication preferences, it makes sense to try to match patient preferences with the physician's actual style. Such matching respects patient autonomy and might enhance patient satisfaction with and trust in their medical providers. ${ }^{16,53}$ However, 29\% of patients do not experience their preferred physician communication style with respect to decision making, with greater mismatch among patients of low socioeconomic status (E. Murray, MD, et al., unpublished data, September 2004). Better congruence might be attained in several ways.

First, as our qualitative data suggest, some degree of patient-driven matching occurs when patients choose their primary care physicians. ${ }^{53}$ However, patient-driven matching has drawbacks. Frequently changing providers is inefficient. Moreover, socioeconomically disadvantaged or less empowered patients may not be able to seek out their physicians of choice. $^{50}$

Second, physicians might modify their communication style to match patient preferences. Physicians often use a more directive, or "paternalistic" style with older, less educated, and sicker patients and a more patient-centered style with younger, better educated, and more socioeconomically advantaged patients. ${ }^{54-57}$ However, it is not clear whether these variations are physician responses to individual patient preferences or demographic characteristics. Because physicians often inaccurately predict patient expectations, ${ }^{58}$ even those who consciously modify their 
communication may fail to match individuals' preferences. Furthermore, physicians demonstrate only limited flexibility with respect to communication style, with over $50 \%$ adopting a single communication style during the majority of their clinical encounters. ${ }^{42}$

Third, health care organizations might match patients and physicians on the basis of communication preferences. One randomized trial gave intervention patients provider demographic characteristics, training, and decision-making orientation and had them choose their primary care provider. Although intervention patients reported greater satisfaction and were more likely to have retained their providers at 1 year, the independent contribution of giving information on decision-making orientation was nonsignificant. ${ }^{53}$

Any approach to matching patient-physician communication styles would require an accurate, efficient way of identifying patient communication preferences. In our study, even the strongest predictor of communication preference, the participant's own physician's style, misclassified many patients. Other studies also suggest that inferring patient preferences from demographic or clinical features would result in substantial misclassification. ${ }^{22,49,51}$ Alternatively, physicians could elicit patient preferences by directly asking patients. Some of our study questions appear promising for this purpose but require validation.

In addition to these practical challenges, there are ethical concerns about matching patients to physicians on the basis of preferred communication style. First, patient preferences for a biomedical style may be uninformed. Older and less educated patients are less likely to experience patient-centered communication ${ }^{54-57}$ and thus may be unfamiliar with it. Our qualitative findings suggest that such patients may perceive it as foreign to the physician's role. Second, more patients might prefer a patient-centered style if they were exposed to good exemplars of it. In several studies, patients who initially expressed little interest in participating in decision making were more satisfied when they experienced more participation than they initially desired and when they felt that their doctor facilitated such participation. ${ }^{59,60}$ Finally, studies report that patientcentered communication is associated with superior adherence to medical recommendations, visit satisfaction,

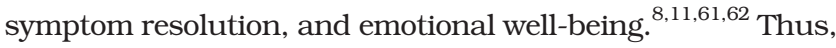
encouraging patient-centered communication may promote patients' best interests. Hence, for patients who prefer a biomedical physician, there may be a tension between respecting their preferences and enhancing their best interests. Physicians should generally respect informed patient choices about their medical care. However, doctors also have obligations to ascertain whether potentially harmful patient choices are truly informed and to try to help patients become better informed. ${ }^{63}$

\section{Implications Regarding CAM Disclosure}

Patient centeredness is believed to enhance open communication and information disclosure. ${ }^{64-66}$ However, we found that participants whose regular physician used a patient-centered style were no more likely to disclose their CAM use than those whose regular physician was not patient centered. Empirical studies of "sensitive" topics, such as HIV risk behaviors and alcohol use, have found that direct, relatively close-ended questions actually enhance accurate disclosure. ${ }^{67-69}$ Our findings provide some empirical support for asking patients routinely and directly about their use of CAM. ${ }^{36-38}$

\section{Limitations}

Our study had several important limitations. Patient responses to simulated videotape scenarios may not reflect their communication preferences during actual physician visits. Although no studies have directly compared patient preferences assessed by ratings of videotapes to those in actual patient-physician interactions, several lines of evidence support the validity of videotape methodology for evaluating patient preferences. First, data from our study and two others that used videotape methodology ${ }^{22,51}$ resemble preference differences observed in nonvideotape studies. ${ }^{16,48,49}$ Also, one study found that patients who received their preferred treatment after evaluating videotape presentations of treatment alternatives had superior therapeutic outcomes to those who received their nonpreferred treatment, ${ }^{70}$ suggesting that videotape-based choices may have predictive validity with respect to clinical outcomes. Finally, our videotape design has several potential methodologic strengths. It avoids the positively skewed satisfaction scores that occur when patients rate their own physician $^{4,71,72}$ and standardizes communication styles and controls for other physician and visit characteristics.

The preference of most patients for the patient-centered doctor may reflect responses to aspects of the videotaped doctors other than communication style, such as tone or mannerism. For example, because the patient-centered versions were slightly longer than the biomedical ones, patients may have perceived the latter as more time efficient or the former as spending more time with patients. We did minimize differences in videotape length and standardized the patient-centered and biomedical versions of each scenario with respect to the doctor's recommendation about CAM use. Alternatively, given our sample's high rates of CAM use, our finding that a majority preferred the patient-centered doctor could have arisen if participants perceived the biomedical doctor as being more critical of CAM. However, in multivariable analysis, regarding the videotaped doctor as open-minded was not a predictor of the respondent's preference for a videotaped physician.

Finally, simultaneously varying several factors (patient and doctor gender, ethnicity, age) in each CAM scenario could have led to spurious findings regarding preferences for a given communication style. The association of gender concordance with communication style preference on bivariate analysis supports this possibility, and our sample 
size and study design limited our power to detect other similar interactions. However, gender concordance was not a significant predictor on multivariate analysis of communication style, and neither age nor ethnicity concordance were significantly associated with communication style on bivariate analysis. In addition, a majority of participants preferred the patient-centered doctor across all three CAM scenarios with varying gender, ethnicity, and age pairings of the videotaped actors. Moreover, both the qualitative data and the Likert scale ratings of physician communication (Table 4) suggest that participants discerned and made choices based on distinct elements of the doctor's communication style. The Likert scale ratings, which participants completed immediately after viewing each videotape, also validate that participants responded at least in part to patient-centered communication skills.

Participants in our study were more likely to prefer the most recently viewed videotape. Other studies, including one videotape study, ${ }^{73}$ have reported a similar recency effect. ${ }^{75,76}$ Because our participants were randomized to view different tape orders (biomedical first vs. patient-centered first), our study design controlled for this effect with respect to our main outcome of preferred physician communication style. Moreover, our finding that four other variables remained significant predictors of communication preference after controlling for tape order in the multivariate analysis suggests that a recency effect could account only partially for participants' communication preferences.

Our findings may not generalize to other clinical settings, patient populations, or clinical problems. First, discussions regarding CAM use may not be typical of other physician-patient interactions. However, CAM use may involve value conflicts or issues of behavioral change and, hence, may resemble other interactions that physicians find challenging and for which they need skillful communication. Second, our relatively young, healthy urgent care population from an academic medical center may not be representative of many general internal medicine practices. ${ }^{76-78}$ However, given that young, healthy patients are more likely to prefer a patient-centered approach, our finding that a significant proportion of our sample preferred a biomedical approach would likely be borne out in populations that include more older patients.

Finally, asking participants to choose between a patientcentered and biomedical doctor precludes a more nuanced understanding of which elements of each physician communication style patients prefer and how this varies during different portions of the clinical encounter or in specific clinical contexts. For example, patients who ordinarily prefer a patient-centered communication style might want a more directive approach if they needed emergency surgical care. Furthermore, patients may have different communication preferences for interactions with their primary care providers than for those with physician subspecialists. Ultimately, skillful communication may entail knowing how to elicit and adapt to patient preferences over time and in different clinical contexts.

\section{Conclusion}

In conclusion, our empirical findings challenge unexamined assumptions regarding the desirability of patientcentered communication and raise ethical and practical questions for clinicians, educators, and medical researchers about matching patients and physicians on the basis of communication style. For patients who prefer a biomedical communication style, clinicians currently face a dilemma. Given that patient-centered communication has been linked to improved outcomes even among patients who do not initially prefer it, clinicians may choose to explain the benefits of a patient-centered approach and encourage all patients to adopt it. ${ }^{79-82}$ However, some patients who prefer a more directive, biomedical style may view this approach as paternalistic or incompetent. Further research is needed to elucidate which elements of patientcentered and biomedical communication patients want in a specific clinical situation or portion of the interview. Clarifying these issues will enable clinicians to adopt a nuanced, flexible approach to the medical interview that both respects informed patient preferences regarding communication and promotes better patient outcomes.

This work was supported by the Robert Wood Johnson Foundation Initiative on Strengthening the Patient-Provider Relationship.

The authors gratefully acknowledge the contributions of Jesse Canchola, MS for his assistance with our data analysis and Elizabeth Murray, MRCGP, PhD for her valuable comments and suggestions. We also wish to thank Ralph Gonzales, MD and Jason Satterfield, PhD for their critical reviews of the manuscript, Paul Nadler for invaluable assistance with study execution, and the editors and anonymous reviewers at JGIM for their insightful contributions.

\section{REFERENCES}

1. Lipkin M, Putnam SM, Lazare A. The Medical Interview: Clinical Care, Education, and Research. New York, NY: Springer-Verlag; 1995.

2. Stewart MA. Effective physician-patient communication and health outcomes: a review. CMAJ. 1995;152:1423-33.

3. Platt FW, Gaspar DL, Coulehan JL, et al. "Tell me about yourself": the patient-centered interview. Ann Intern Med. 2001;134:107985.

4. Williams S, Weinman J, Dale J. Doctor-patient communication and patient satisfaction: a review. Fam Pract. 1998;15:480-92.

5. Kinnersley P, Stott N, Peters TJ, Harvey I. The patient-centredness of consultations and outcome in primary care. Br $\mathrm{J}$ Gen Pract. 1999;49:711-16.

6. Kinmonth AL, Woodcock A, Griffin S, Spiegal N, Campbell MJ. Randomised controlled trial of patient centred care of diabetes in general practice: impact on current wellbeing and future disease risk. The Diabetes Care from Diagnosis Research Team. BMJ. 1998;317:1202-8.

7. Rosenberg EE, Lussier MT, Beaudoin C. Lessons for clinicians from physician-patient communication literature. Arch Fam Med. 1997;6:279-83.

8. Safran DG, Taira DA, Rogers WH, Kosinski M, Ware JE, Tarlov AR. Linking primary care performance to outcomes of care. J Fam Pract. 1998;47:213-20 
9. Rao JK, Weinberger M, Kroenke K. Visit-specific expectations and patient-centered outcomes: a literature review. Arch Fam Med. 2000;9:1148-55.

10. Maisiak R, Austin JS, West SG, Heck L. The effect of person-centered counseling on the psychological status of persons with systemic lupus erythematosus or rheumatoid arthritis: a randomized, controlled trial. Arthritis Care Res. 1996;9:60-6.

11. Kaplan SH, Greenfield S, Ware JE Jr. Assessing the effects of physician-patient interactions on the outcomes of chronic disease. Med Care. 1989;27(3 suppl):S110-S127.

12. Levinson W, Roter DL, Mullooly JP, Dull VT, Frankel RM. Physicianpatient communication. The relationship with malpractice claims among primary care physicians and surgeons. JAMA. 1997;277:5539.

13. Jackson JL, Kroenke K, Chamberlin J. Effects of physician awareness of symptom-related expectations and mental disorders. A controlled trial. Arch Fam Med. 1999;8:135-42.

14. Kravitz RL, Cope DW, Bhrany V, Leake B. Internal medicine patients expectations for care during office visits. J Gen Intern Med. 1994;9:75-81.

15. Kravitz RL, Callahan EJ, Azari R, Antonius D, Lewis CE. Assessing patients' expectations in ambulatory medical practice. Does the measurement approach make a difference? J Gen Intern Med. 1997;12:67-72.

16. Krupat E, Rosenkranz SL, Yeager CM, Barnard K, Putnam SM, Inui TS. The practice orientations of physicians and patients: the effect of doctor-patient congruence on satisfaction. Patient Educ Couns. 2000;39:49-59.

17. Stewart M, Brown JB, Donner A, et al. The impact of patientcentered care on outcomes. J Fam Pract. 2000;49:796-804.

18. Levinson W, Roter D. The effects of two continuing medical education programs on communication skills of practicing primary care physicians. J Gen Intern Med. 1993;8:318-24.

19. Krupat E, Bell RA, Kravitz RL, Thom D, Azari R. When physicians and patients think alike: patient-centered beliefs and their impact on satisfaction and trust. J Fam Pract. 2001;50:1057-62.

20. Smith RC, Lyles JS, Mettler J, et al. The effectiveness of intensive training for residents in interviewing. A randomized, controlled study. Ann Intern Med. 1998;128:118-26.

21. Brown JB, Boles M, Mullooly JP, Levinson W. Effect of clinician communication skills training on patient satisfaction. A randomized, controlled trial. Ann Intern Med. 1999;131:822-9.

22. McKinstry B. Do patients wish to be involved in decision making in the consultation? A cross sectional survey with video vignettes. BMJ. 2000;321:867-71.

23. Eisenberg DM, Kessler RC, Foster C, Norlock FE, Calkins DR, Delbanco TL. Unconventional medicine in the United States. Prevalence, costs, and patterns of use. N Engl J Med. 1993;328:24652.

24. Eisenberg DM, Davis RB, Ettner SL, et al. Trends in alternative medicine use in the United States, 1990-1997: results of a followup national survey. JAMA. 1998;280:1569-75.

25. Wolsko PM, Eisenberg DM, Davis RB, Ettner SL, Phillips RS. Insurance coverage, medical conditions, and visits to alternative medicine providers: results of a national survey. Arch Intern Med. 2002;162:281-7.

26. Wolsko PM, Eisenberg DM, Davis RB, Phillips RS. Use of mind-body medical therapies. J Gen Intern Med. 2004;19:43-50.

27. Foster DF, Phillips RS, Hamel MB, Eisenberg DM. Alternative medicine use in older Americans. J Am Geriatr Soc. 2000;48:1560-5.

28. Ernst E. The risk-benefit profile of commonly used herbal therapies: Ginkgo, St. John's Wort, Ginseng, Echinacea, Saw Palmetto, and Kava. Ann Intern Med. 2002;136:42-53.

29. Piscitelli SC, Burstein AH, Chaitt D, Alfaro RM, Falloon J. Indinavir concentrations and St. John's wort. Lancet. 2000;355:547-8.

30. Verhoef MJ, Hagen N, Pelletier G, Forsyth P. Alternative therapy use in neurologic diseases: use in brain tumor patients. Neurology. $1999 ; 52: 617-22$.
31. Paltiel O, Avitzour M, Peretz T, et al. Determinants of the use of complementary therapies by patients with cancer. J Clin Oncol. 2001;19:2439-48.

32. Boon H, Brown J, Gavin A. What are the experiences of women with breast cancer as they decide whether to use complementary/ alternative medicine? West J Med. 2000;173:39.

33. Singh N, Squier C, Sivek C, Nguyen MH, Wagener M, Yu VL. Determinants of nontraditional therapy use in patients with HIV infection. A prospective study. Arch Intern Med. 1996;156:197-201.

34. Burstein HJ, Gelber S, Guadagnoli E, Weeks JC. Use of alternative medicine by women with early-stage breast cancer. N Engl J Med. 1999;340:1733-9.

35. Holland JC. Use of alternative medicine-a marker for distress? N Engl J Med. 1999;340:1758-9.

36. Perlman AI, Eisenberg DM, Panush RS. Talking with patients about alternative and complementary medicine. Rheum Dis Clin North Am. 1999;25:815-22.

37. Sugarman J, Burk L. Physicians' ethical obligations regarding alternative medicine. JAMA. 1998;280:1623-5.

38. Eisenberg DM. Advising patients who seek alternative medical therapies. Ann Intern Med. 1997;127:61-9.

39. Patterson RE, Neuhouser ML, Hedderson MM, et al. Types of alternative medicine used by patients with breast, colon, or prostate cancer: predictors, motives, and costs. J Altern Complement Med. 2002;8:477-85.

40. Lazar JS, O'Connor BB. Talking with patients about their use of alternative therapies. Prim Care. 1997;24:699-714.

41. Brown J, Stewart M, McCracken E, McWhinney IR, Levenstein J. The patient-centred clinical method. 2. Definition and application. Fam Pract. 1986;3:75-9.

42. Roter DL, Stewart M, Putnam SM, Lipkin M Jr, Stiles W, Inui TS. Communication patterns of primary care physicians. JAMA. 1997:277:350-6.

43. Brown J, Stewart M, Ryan BL. Assessing Communication Between Patients and Physicians: The Measure of Patient-centered Communication (MPCC). London, Ontario: Centre for Studies in Family Medicine; 2001.

44. Wolf MH, Putnam SM, James SA, Stiles WB. The Medical Interview Satisfaction Scale: development of a scale to measure patient perceptions of physician behavior. J Behav Med. 1978;1:391-401.

45. Hulley SB. Designing Clinical Research: An Epidemiologic Approach. 2nd ed. Philadelphia, Pa: Lippincott Williams \& Wilkins; 2001.

46. Hosmer DW, Lemeshow S. Applied Logistic Regression. New York, NY: Wiley; 1989.

47. Krupat E, Yeager CM, Putnam SM. Patient role orientations, doctorpatient fit, and visit satisfaction. Psychol Health. 2000;15:707-19.

48. Parker PA, Baile WF, de Moor C, Lenzi R, Kudelka AP, Cohen L. Breaking bad news about cancer: patients' preferences for communication. J Clin Oncol. 2001;19:2049-56.

49. Benbassat J, Pilpel D, Tidhar M. Patients' preferences for participation in clinical decision making: a review of published surveys. Behav Med. 1998;24:81-8.

50. Schmittdiel J, Grumbach K, Selby JV, Quesenberry CP Jr. Effect of physician and patient gender concordance on patient satisfaction and preventive care practices. J Gen Intern Med. 2000;15:761-9.

51. Dowsett SM, Saul JL, Butow PN, et al. Communication styles in the cancer consultation: preferences for a patient-centred approach. Psychooncology. 2000;9:147-56.

52. Savage R, Armstrong D. Effect of a general practitioner's consulting style on patients' satisfaction: a controlled study. BMJ. 1990;301:968-70.

53. Hsu J, Schmittdiel J, Krupat E, et al. Patient choice. J Gen Intern Med. 2003;18:319-25.

54. Roter D, Hall JA. Doctors Talking with Patients/Patients Talking with Doctors: Improving Communication in Medical Visits. Westport, Conn: Auburn House; 1992.

55. Kaplan RM, Hammel B, Schimmel LE. Patient information processing and the decision to accept treatment. J Soc Behav Pers. $1985 ; 1: 113-20$. 
56. Greene MG, Adelman R, Charon R, Hoffman S. Ageism in the medical encounter: an exploratory study of the doctor-elderly patient relationship. Lang Commun. 1986;6:113-24.

57. Waitzkin H. Information giving in medical care. J Health Soc Behav. 1985;26:81-101.

58. Hall JA, Stein TS, Roter DL, Rieser N. Inaccuracies in physicians' perceptions of their patients. Med Care. 1999;37:1164-8.

59. Golin C, DiMatteo MR, Duan N, Leake B, Gelberg L. Impoverished diabetic patients whose doctors facilitate their participation in medical decision making are more satisfied with their care. J Gen Intern Med. 2002;17:857-66.

60. Tennstedt SL. Empowering older patients to communicate more effectively in the medical encounter. Clin Geriatr Med. 2000;16:6170, ix.

61. Brody DS, Miller SM, Lerman CE, Smith DG, Caputo GC. Patient perception of involvement in medical care: relationship to illness attitudes and outcomes. J Gen Intern Med. 1989;4:506-11.

62. Roter DL, Hall JA, Kern DE, Barker LR, Cole KA, Roca RP. Improving physicians' interviewing skills and reducing patients emotional distress. A randomized clinical trial. Arch Intern Med. 1995; 155:1877-84.

63. Lo B. Resolving Ethical Dilemmas: A Guide for Clinicians. 2nd ed. Philadelphia, Pa: Lippincott Williams \& Wilkins; 2000.

64. Lazare A, Putnam SM, Lipkin M. The three functions of the medical interview. In: Lipkin M, Putnam SM, Lazare A, eds. The Medical Interview: Clinical Care, Education, and Research. New York, NY: Springer-Verlag; 1995:3-19.

65. Beckman HB, Frankel RM. The effect of physician behavior on the collection of data. Ann Intern Med. 1984;101:692-6.

66. Burack RC, Carpenter RR. The predictive value of the presenting complaint. J Fam Pract. 1983;16:749-54.

67. Floyd M, Lang F, Beine KL, McCord E. Evaluating interviewing techniques for the sexual practices history. Use of video trigger tapes to assess patient comfort. Arch Fam Med. 1999;8:218-23.

68. Gmel G, Lokosha O. Self-reported frequency of drinking assessed with a closed- or open-ended question format: a split-sample study in Switzerland. J Stud Alcohol. 2000;61:450-4.

69. Ivis FJ, Bondy SJ, Adlaf EM. The effect of question structure on self-reports of heavy drinking: closed-ended versus open-ended questions. J Stud Alcohol. 1997;58:622-4.

70. Devine DA, Fernald PS. Outcome effects of receiving a preferred, randomly assigned, or non-preferred therapy. J Consult Clin Psych. 1973;41:104-7

71. Oberst MT. Methodology in behavioral and psychosocial cancer research. Patients' perceptions of care. Measurement of quality and satisfaction. Cancer. 1984;53(10 suppl):2366-75.

72. Brown R, Dunn S, Butow P. Meeting patient expectations in the cancer consultation. Ann Oncol. 1997;8:877-82.

73. Gerbert B, Berg-Smith S, Mancuso M, et al. Video study of physician selection: preferences in the face of diversity. J Fam Pract. 2003;52:552-9.

74. Baddeley AD. The Psychology of Memory. New York, NY: Basic Books; 1976.

75. Capitani E, Della Sala S, Logie RH, Spinnler H. Recency, primacy, and memory: reappraising and standardising the serial position curve. Cortex. 1992;28:315-42.

76. Yunker RM, Levine MK, Sajid AW. Freestanding emergency centers and the patient population of internists. South Med J. 1986;79:424-7.

77. Yunker RM, Levine MK, Sajid AW. Free-standing emergency centers and the patient population of family physicians. J Fam Pract. 1985;21:63-9.

78. Rylko-Bauer B. The development and use of freestanding emergency centers: a review of the literature. Med Care Rev. 1988;45:129-63.

79. Lo B, Quill T, Tulsky J. Discussing palliative care with patients ACP-ASIM End-of-life Care Consensus Panel. American College of Physicians-American Society of Internal Medicine. Ann Intern Med. 1999; 130:744-9.

80. Towle A, Godolphin W. Framework for teaching and learning informed shared decision making. BMJ. 1999;319:766-71.

81. Sheridan SL, Harris RP, Woolf SH. Shared decision making about screening and chemoprevention. A suggested approach from the U.S. Preventive Services Task Force. Am J Prev Med. 2004;26:56-66.

82. Platt FW, Gordon GH. Field Guide to the Difficult Patient Interview. Philadelphia, Pa: Lippincott Williams \& Wilkins; 1999. 


\section{Appendix A: Important Aspects of Doctoring}

Respondents were asked to rate the perceived importance of each of the items below by using a 5-point Likert scale that ranged from (1) irrelevant to (5) extremely important.

"Thinking about different aspects of medical care that someone receives from a doctor, how important to you are each of the following:"

\section{Item}

Number

\section{Doctoring Characteristic}

(1) the doctor's interest in you as a person

(2) the doctor's ability to communicate clearly with you

(3) the doctor listens to your concerns and questions

(4) the doctor is open-minded

(5) the doctor is decisive

(6) the doctor suggests a good plan to improve your health

(7) the doctor has excellent medical skills

\section{Appendix B: Physician Assessment Questionnaire}

Respondents were asked to rate their level of agreement or disagreement with the following statements regarding the videotapes. Question 1 utilized a 5-point Likert scale ranging from (1) definitely yes to (5) definitely not. All remaining questions utilized a 7-point Likert scale ranging from (1) very strongly agree to (7) very strongly disagree. Items here are numbered and grouped for clarity; in the original questionnaire, "patient-centered" and "other" characteristics were interspersed, followed by "global" measurements.

\section{Patient-Centered Characteristics}

(1) The doctor suggested a good plan for helping the patient.

(2) The doctor seemed narrow-minded.

(3) The doctor was interested in the patient as a person.

(4) The doctor gave the patient a chance to say what was on his or her mind.

(5) The doctor gave the patient his/her full attention.

\section{Other Characteristics}

(6) The doctor took the patient's problems seriously.

(7) The doctor communicated in simple, clear language.

(8) The doctor seemed to know about the risks and benefits of alternative medicine.

(9) The doctor seemed indecisive.

\section{Global Measurements}

(10) This is a doctor I would trust.

(11) I would recommend this doctor to my friends. 